\title{
Matrix Analysis of Significant Causes of Threats to Economic Security in Forest Sector of Economy
}

Igor A. Vasilyev

Artem V. Konstantinov

Oleg I. Vasilyev

Ivan 0. Torzhkov

St. Petersburg Forestry Research Institute, Saint Petersburg, Russian Federation

Doi:10.5901/mjss.2016.v7n2p228

\begin{abstract}
At present, the state of forest sector of Russia is determined by capability for preservation of sustainability under the influence of external and internal destabilizing factors and for developing and adapting to changing economic and other conditions. Solving the task of provision of economic security should be based on the systematization of main indicators which allow evaluating the state of forest-based sector quickly and authentically, as well as on determination of key limits of value of corresponding indicators. In order to build a profile of reasons' influence on the emergence of threats to economic security, a matrix analysis was used - it allows determining the evaluation of relative significance of reasons. The experts chose the most significant causes in the group of natural and climatic causes: aggravation of timber and raw potential of forests, negative natural factors (wood diseases, pests), in the group of anthropogenic causes - illegal cuttings, imperfection of practice of wood protection from fire, imperfect forest and related laws, and in the group of economic causes - low demand for forest products, non-conformity of the quality of prepared products to the global standards. Results of the conducted integral evaluation allowed determining the level of influence of causes for emergence of critical and catastrophic threats in forest-based sector. Emergence of threats to economic security is determined by many factors: external and internal, subjective and objective, low level of knowledge on the nature of threat, state's needs in economic development, nature \& climatic and anthropogenic changes, imperfection of the mechanism of opposition to threats to economic security, imperfection of laws, errors in economic activities, narrow time limits for decision making, aggravation of the threat to economic security from wrong economic actions, and contradictions in political and economic interests. Considering this, unification of efforts for opposition and neutralization of threats to economic security are the task of all subjects of forest relations.
\end{abstract}

Keywords: economic security, matrix analysis, significance of causes, threats

\section{Introduction}

At present, the state of forest sector of Russia is determined by capability for preservation of sustainability under the influence of external and internal destabilizing factors and for developing and adapting to changing economic and other conditions (Konstantinov, 2014). Therefore, there arises necessity for development of modern mechanisms of provision of economic security of forest-based sector of Russia and their consecutive implementations. A very important role belongs to effective regulation of business, balance of entrepreneurial competitive environment, formation of stimuli and sources for investments and innovations, and search for the most profitable niches in the external markets. There is also a need for development of such mechanisms of provision of economic security of forest-based sector that will not allow excessive growth of dependence on international financial organizations, turning forest-based sector into the source of cheap raw materials and sales market for final products for neighboring countries, and will allow implementing the strategy of recovery of positions at the global market (Morkovina, 2014).

Solution of this problem should be based on the systematization of main indicators of economic security which allow evaluating the state of forest-based sector quickly and authentically, as well as on determination of key limits of value of corresponding indicators.

The purpose of this research is conduct of matrix analysis of the causes of emergence of threats to economic security in forest-based sector of economy which reflect the necessity for consideration of conflicts of interests of members of the system of economic security provision. 
ISSN 2039-2117 (online)

ISSN 2039-9340 (print)
Mediterranean Journal of Social Sciences MCSER Publishing, Rome-Italy
Vol 7 No 2 March 2016 